\title{
AZUL PROFUNDO: ESCULPINDO UM DIAMANTE CRISTALINO DO E NO PENSAMENTO $^{1}$
}

\author{
AZUL PROFUNDO: ESCULPIENDO UN DIAMANTE CRISTALINO DEL Y EN EL \\ PENSAMIENTO
}

\begin{abstract}
Sebastian Wiedemann ${ }^{2}$
Resumo: Esta experimentação por meio do plano das textualidades se dispõe como um gesto de cuidado da vida e do cenário e fabulação especulativa que nas próprias linhas da escrita se desdobram. Um gesto de afirmação da potência do cinema como mineração às avessas, que nada extrai, mas que engravida a terra e a vida. Escrita como proposta de uma mina autoprodutiva de diamantes cinematográficos que mantem o cosmos aberto e onde os corpos reescrevem sua potência genética como trans-evolução, na qual acontecem como cristais temporais, como matéria geológica e embrionária.
\end{abstract}

Palavras-chave: Virtual; corpo larval; Deleuze.

Resumen: Esta experimentación por medio del plano de las textualidades se dispone como un gesto de cuidado de la vida y del escenario y fabulación especulativa que en las propias líneas de la escritura se despliega. Un gesto de afirmación de la potencia del cine como minería al revés, que nada extrae, pero que embaraza la tierra y la vida. Escritura como propuesta de una mina auto-productiva de diamantes cinematográficos que mantienen el cosmos abierto y donde los cuerpos reescriben su potencia genética como trans-evolución, en la cual se manifiestan como cristales temporales, como materia geológica y embrionaria.

Palabras claves: Virtual; cuerpo larval; Deleuze.

Recomeçar. Mais uma vez como gesto, se abismar no Azul Profundo como plano de experiência, como plano cósmico e de fuga. Voltar a ele com um certo esquecimento e ao mesmo tempo com uma memória mais Azul, mas Profunda. Sentir no corpo uma certa suspensão em meio à densidade das múltiplas atmosferas e esgotamento que tem feito de nós uma tela, uma membrana multidimensional onde junto com o mundo acontecemos como matéria-luz que não para de difratar o cinematografo cósmico como esculpir dinâmico de um diamante cristalino.

No entanto, esta é uma espécie de percepção externa, quando o que aqui nos move em meio ao esgotamento de estar no profundo do azular, é uma vontade perversa de querer liquidificar estas palavras e injetá-las diretamente na veia dos corpos ou, talvez, como uma injeção de adrenalina, injetá-las direto no coração. Assim, quem sabe, os corpos que se achegam

\footnotetext{
${ }^{1}$ Uma primeira versão deste texto foi apresentada no evento "VIII Seminário Conexões: Deleuze e Corpo e Cena e Máquina e..." na Unicamp - Universidade Estadual de Campinas em novembro de 2019. Diante da iminência dos acontecimentos ocorridos no dia anterior, isto é, no dia 10 de novembro de 2019, como parte da contingência e improviso do momento, a modo de preambulo da minha fala, disse para a plateia as seguintes palavras: "Antes de tudo cuidar, cuidar a vida, cuidar este cenário e fabulação especulativa. Então acolher a história do pensamento como a emergência de percepções alucinadas. Isto é, abraçar a potência criadora do delírio e da desrazão que ajudam a sentir no corpo que a política é um problema de percepção. O poder que promove golpes de estado, como o que está acontecendo na Bolívia, vê no Salar de Uyuni matéria prima, recursos a serem extraídos. Em contrapartida, a potência do cinema que aqui quero apresentar é a de uma mineração às avessas, que nada extrai, mas que engravida a terra e a vida. Em oposição e em resistência a uma mina de lito a céu aberto, proponho uma mina auto-produtiva de diamantes cinematográficos que mantem o cosmos aberto".

${ }^{2}$ Cineasta-pesquisador e filosofo. Doutorando em Educação no OLHO - Laboratório de Estudos Audiovisuais, Faculdade de Educação - Unicamp.E-mail: wiedemann.sebastian@gmail.com.
} 
a este gesto, possam sentir, possam ter uma percepção interna do que acontece quando não só deixamos de ser vertebrados, mas ao mesmo tempo devimos faces de um diamante cristalino.

Uma percepção interna, uma adrenalina e vertigem, só suportável por um corpo larval. O que faz com que querer incubar tal percepção implique se abrir a receber uma injeção, que nos faz involução do tempo humano demasiado humano que nos transveste. Isto é, se abrir a receber uma intervenção de biotecnologia sensorial que reescreva nossa potência genética como transevolução, onde os corpos possam acontecer como cristais.

Tal transcrição genética, e como veremos física, de repente nos obriga a mergulhar na Mata Atlântica, onde mora a única espécie bioluminiscente emissora de luz azul do continente sul-americano, uma larva de mosquito, a Neoceroplatus betaryiensi ${ }^{3}$, cujos substratos e enzimas ao entrar em processo de simbiogênese e transgenia conosco, não só ativam em nós uma potência larval, mas sobretudo azulante.

No entanto, é só no Azul profundo que tal mutação que agora somos, pode se dizer cristal temporal. Tudo que resiste e insiste no Azul profundo é mutagênico, dali a des-memória que se faz atmosfera circundante e o esgotamento insistente pelas baixas temperaturas que fazem possível, não só a quebra de simetria espacial, mas, sobretudo, a quebra de simetria temporal e que permitem afirmar algo que Bergson já faz muito intuía e que Deleuze reafirmou. O fato de que afirmar a vida é o incessante esculpir quântico de um diamante cristalino do tempo e que graças às ideias do físico Frank Wilczek ${ }^{4}$ agora sabemos que não é só um estado espiritual da matéria, mas também um estado físico.

Recomeçar. Mais uma vez se hibridar Azul Profundo. Poderíamos dizer como Spinoza, O que pode um corpo? Poderíamos colocar o problema desde uma perspectiva pragmática e como William James, dizer, Como fazer com que o pensamento não abandone o corpo? ou em outras palavras, Como não abandonar a experiência pura do pensamento que se faz corpo? Fazer corpo com, como aquele gesto que não perde de vista as relações internas entre as componentes que dão consistência ao próprio corpo e que por sua vez sempre é corpo de corpos. Corpo extrahumano e larval que se transveste de azul. Corpo do tempo, cor do tempo, Azul que compõe e complica o diamante cristalino.

Pensar com, pensar sendo parte de, fazendo corpo com a memória azulante do mundo. Isto é, compartilhando o mesmo tempo e espaço, compartilhando a mesma dimensão e superfície com os eventos que nos convidam a comparecer, a par com eles ser, enquanto devires que entre-vivem. Uma recusa do diferir cronológico para poder abrir e intensificar um diferir e um diferencial no acontecer do acontecimento. Dar um salto do extensivo ao intensivo. Entrar no Azul Profundo, como paradoxal ilocalizabilidade do pensamento que pressupõe a suspensão de esquemas perceptivos já dados, para se abrir a uma topologia diagramática e acentrada de fluxos contínuos e cortes diferenciadores em relações de limites dinâmicos singulares e situados.

Nesse entorno de turbulências e tendências catastróficas que mantém o pensamento em movimento, é onde continua a se desdobrar o atractor perceptivo e perspectivístico que é o Azul profundo, como esse cenário e fabulação especulativa (HARAWAY, 2013), como essa dobra e redobra infindável de ecologias azuis e azulantes que inevitavelmente ressoam com um oceano,

\footnotetext{
${ }^{3}$ Cf. O mosquito brilhante do Vale do Ribeira. https://revistapesquisa.fapesp.br/2019/09/06/o-mosquito-brilhantedo-vale-do-ribeira/.

${ }^{4}$ Cf. "The Exquisite Precision of Time Crystals": https://www.scientificamerican.com/article/the-exquisite-precisionof-time-crystals/ e "It's Official: Time Crystals Are a New State of Matter, And Now We Can Create Them": https://www.sciencealert.com/it-s-official-time-crystals-are-a-new-crazy-state-of-matter-and-now-we-can-create-them.
} 
com uma aquosidade monadica e incomensurável onde o virtual e atual talvez encontrem seu circuito mais ínfimo, seu inframince (MANNING, 2016). E que por sua vez é o epicentro dos cristais do tempo, onde os possíveis em estado puro de germe e gênese proliferam e pipocam em todas as direções e no maior grau de intensidade. Azul profundo, como a tonalidade afetiva que escava e pole superfícies temporais dando lugar a um diamante quântico que fractaliza e difrata a experiência tornando-a múltipla e mais rica.

Mais uma vez, recomeçar. Desta vez dançando. Fazer dançar o Azul Profundo, fazer dançar a percepção, fazer dela uma condição alucinada. Matéria prima e cerne do cristalino da vida, da alucinação singular que habitamos e nos habita. Fazer durar a dança, o ritmo que destila. Não deixar que o cristal se dissipe, que seja esquecimento, mas pelo contrário que seja memória ativa, sempre disponível para o futuro. Esculpir a conservação de todos os tempos, das suas múltiplas dimensões que se superpõem intensivamente, enquanto nós como percepção interna somos matéria do próprio tempo. Nós, como telas e membranas, como dobras, polimentos e escavações do tempo, cuja cor Azul nos esculpe sem escultor.

Tudo como marulho e murmulho do Azul profundo, tudo como gotas diamantinas, como lentes multifacetadas e multidimensionais por onde o cinematografo cósmico projeta a multiplicidade e heterogeneidade do vivente. Nós, dançando, pertencendo ao tempo, à luz, ao Azul Profundo. A injeção continha tempo puro, como soro vital. Continha a potência farmacológica de abrir os corpos a esse processo metamórfico de acolher e abraçar nas suas dobras e tecidos esse outro estado da matéria, esse azul dos cristais do tempo e das larvas bioluminiscentes da Mata Atlântica.

Eis que como entre-viver e co-evolução azulante e criadora, o Azul Profundo se manifesta como plano de composição temporal. Abandonamos tudo, até nossa morfologia e humanidade, nos abandonamos pura força vivente e azulante, nos esgotamos, somos resto de resto, devimos extremófilos ${ }^{5}$, devimos qualidade alucinada, mutante e bizarra de vida, devimos impossibilidade, mas é na impossibilidade que o Azul profundo como tonalidade afetiva prolifera e excita. Entreviver cristalino de luz liquida. O Azul profundo é o próprio diamante em ato e em obras. E o pensamento é o esculpir e cinzelar do ponto de vista da criação como condição relacional e impessoal de encontro entre disparidades que devora nossos restos e os liquidifica como potência trans-morfica e trans-existencial. Tempo puro, tempo diamantino que se goteja multiversos. A profundeza do Azul lascando a vida de modo inominável e incontável, mas sempre pululante.

O Azul profundo como esse meio, como essa ocasião intervalar onde os dinamismos perspectivísticos dos cristais são oscilação existencial. Os modos de experiência cinematográficos como a perspectiva do ponto de vista dos corpos que apreende, a cada vez e de modo diferente, o cinematográfico cósmico como difração e variação. Isto é, um caleidoscópio em formação, cuja condição cristalina faz dele um interrogante que se multiplica. O diamante, o Azul Profundo, sem intenção de resolução se autoperguntando: E agora o que você vai fazer? Mas no fundo sabemos que essa é uma pergunta enganosa e que esconde um segredo, o tempo puro. O interrogante nos seus interstícios o que realmente se pergunta é: E agora, como sem sair do agora fazer com que o fazer não seja o que já se fez?

Penetrar então no interrogante que sustenta o diamante sem querer resolver o labirinto que nos leva a seu núcleo. Ali onde o tempo se ergue como potência inorgânica que contém o germe dos mundos. No mais profundo do Azul e que se manifesta em todo lugar como

${ }^{5}$ Cf. "Extremófilos": http://labisismi.fmrp.usp.br/index.php/br/extremofilos. 
superfície temporal, encontramos as duas faces intimas e internas do diamante e que são seu motor genético, o atual e o virtual como disparidade indiscernível (ORLANDI, 2011), como coalescência cosmogenética onde a vida se faz impessoal e a-subjetiva, indiscernível e assignificante, imperceptível e inorgânica (MONTEBELLO, 2017).

Incerteza e indeterminação como condição do azular, do esculpir do cristal que se faz e se desfaz sem parar. Um continuum, um spatium do virtual que não cessa de acolher o atual e vice-versa. Um circuito que como impulso vital secreta as gotas diamantinas do Azul profundo. Isto é, o Azul profundo como força e virtual em curso de atualização, tanto quanto o espaço no qual ele se desloca e desdobra (DELEUZE; PARNET, 1998).

Azul profundo como duplo virtual de todas as ecologias azuis e azulantes que possamos imaginar, como mínimo de determinação, máximo de indeterminação e plena potência de singularização e diferenciação. Produção incessante de efemeridades. Um coexistir, uma perpetua troca de lugar entre atual e virtual, onde o Azul profundo não para de se afirmar como superfície espelhante, como diamante cristalino do e no pensamento.

Uma mina de cristais azuis que não para de ser esculpida por ela mesma e onde nós não paramos de nos desdobrar como matéria geológica e embrionária. É no plano de imanência que os cristais aparecem e nunca o cinema, como cinematografo cósmico esteve tão próximo da geologia e de uma mineração das avessas, onde nada se extrai, mas tudo se reconduz ao seio da terra, ao seio do magma marinho e cristalino do Azul profundo como modos de experiência cinematográficos que produzem diamantes. A agência cineasta não tem outro proposito a não ser a produção de diamantes que multipliquem a luz azul em infinitas direções e dimensões. Individuação como processo, cristalização como cosmogênese.

Todo um intercambio e perspectivismo relacional dos gradientes de existência, onde a força e potência de existir perseveram através da realidade do virtual. O que está em potencial pode vir a ser; e o que tem sido, já estava em potencial. (MASSUMI, 2014) Isto é, as virtualidades que povoam o Azul profundo, enquanto plano de imanência e composição, sempre estão indo em direção a uma qualidade cristalina, sempre estão indo em direção ao ponto crítico de cristalização, ali onde o acontecimento se afirma como cristal (DELEUZE, 2015) na superfície do vivente.

Esculpir como gesto de cuidado, de conservação das condições de possibilidade para que a experiência possa devir a escavação de superfícies cristalinas do Azul profundo, onde o cinema, enquanto processo cosmogenético, não é só um problema de percepção e ótica, mas, antes de tudo, um gesto de imersão oceânica numa politica geológica.

Recomeçar. Insistir em abandonar o Cinema e abismar-se cinema antes de se saber e se dizer cinema. Puro hibridar-se diamantino no processo cosmogenético de modos de experiência cinematográficos a-subjetivos. Restos. Larva azul e cristalina como delírio vital. Então, mais uma vez insistir! Mergulhar no Azul profundo para não se afogar, mergulhar por necessidade existencial. Fazer corpo com esta fabulação especulativa para seguir estando em pé, respirando; para continuar sustendo este corpo que escreve e fala, mesmo ao preço de se desmanchar Azul Profundo.

\section{Referências}

DELEUZE, Gilles. Lógica do Sentido. 5. ed. São Paulo: Perspectiva, 2015.

DELEUZE, Gilles; PARNET, Claire. Diálogos. São Paulo: Editora Escuta, 1998. 
HARAWAY, Donna. SF: science fiction, speculative fabulation, string figures, so far. [s. 1.], 2013. Disponível em: https://adanewmedia.org/2013/11/issue3-haraway/. Acesso em: 10 ago. 2019.

MANNING, Erin. Por uma pragmática da inutilidade, ou o valor do inframince. Galáxia, São Paulo, [s. 1.], n. 31, p. 22-40, 2016.

MASSUMI, Brian. Envisioning the virtual: the Oxford handbook of virtuality. [s. 1.], 2014. Disponível em: https://www.oxfordhandbooks.com/view/10.1093/oxfordhb/9780199826162.001.0001/oxfordhb9780199826162-e-010. Acesso em: 10 nov. 2019.

MONTEBELLO, Pierre. Deleuze, esthétiques: la honte d'être un homme. [s.l.]: Les Presses du réel, 2017.

ORLANDI, Luiz B. L. Filosofia com arte. 2011, Palestra no Auditório do IMECC da Unicamp. 